\title{
Impact of Soiling on Energy Yield of Solar PV Power Plant and Developing Soiling Correction Factor for Solar PV Power Forecasting
}

\author{
Sahana L., Naveen Kumar, Hans Peter Waldl, Prasun Kumar Das, \\ Karthik Ramanathan, K. Balaraman, and Indradip Mitra
}

\section{ABSTRACT}

Across the world, the geographical conditions are varied, and the characteristics of dust depend on the local environmental conditions. The solar power generators must incorporate the soiling losses in their estimation for power output and therefore a methodology was developed to estimate the soiling correction factor. After extensive research, a comprehensive review was presented on the effect of soiling on performance of PV plants along with case studies of soiling experiments around the world. A soiling experiment was designed to develop the soiling correction factor. A methodology to calculate the soiling correction factor, which can be implemented in any location, was developed by analyzing the data from the soiling experiment. The effect of rainfall, humidity and wind on soiling was analyzed and documented. The performance of one $20 \mathrm{kWp} \mathrm{PV} \mathrm{plant}$ was monitored to study the effect of weather-related parameters on the performance. The soiling correction factor varied from $-1.36 \%$ to $3.67 \%$ during the period between June 2018 and June 2019 in Chennai. It was observed that the average PV conversion efficiency of the $20-\mathrm{kW}$ plant was $11.75 \%$ and the average $P R$ was $75 \%$. It was observed that the correlation between module temperature and DC power; between humidity and DC power; between GTI and DC power varied every month. The soiling factor developed could be incorporated into the short-term day ahead solar forecasting model. The developed methodology could be applied at the any large-scale solar power plant around the world for yield assessment, designing as well as operational forecasting purposes.

Keywords: Energy Yield, Performance Ratio, Soiling, Solar Power Forecasting.
Published Online: July 14, 2021

ISSN: $2736-5506$

DOI :10.24018/ejenergy.2021.1.3.7

Sahana L.*

Department of Energy and Environment, TERI School of Advanced Studies, Delhi, India.

(e-mail: 1sahana@gmail.com)

Naveen Kumar

National Institute of Wind Energy (NIWE), Chennai, India.

(e-mail: navinem46@ gmail.com)

Hans Peter Waldl

Overspeed GmbH \& Co. KG,

Oldenburg, Germany.

(e-mail: h.p.waldl@ overspeed.de)

Prasun Kumar Das

National Institute of Wind Energy

(NIWE), Chennai, India.

(e-mail: prasuntezu@ gmail.com)

Karthik Ramanathan

National Institute of Wind Energy

(NIWE), Chennai, India

(e-mail: karthikram85@gmail.com)

K. Balaraman

National Institute of Wind Energy

(NIWE), Chennai, India.

(e-mail: dg.niwe@gov.in)

Indradip Mitra

Deutsche Gesellschaft für

Internationale Zusammenarbeit (GIZ),

New Delhi, India.

(e-mail: indradip.mitra ${ }^{@}$ giz.de)

*Corresponding Author

\section{INTRODUCTION}

The PV system efficiency of solar panels is around 15-20\% due to the inherent material property of the panels and this efficiency is further reduced by $10-25 \%$ due to losses in cabling, inverter, and soiling [1]. Research is underway to improve the efficiency of the solar modules and parallelly there is more focus on optimizing the energy yield obtained from the existing PV panels. The energy yield of a solar PV panel majorly depends on geographical location, solar irradiation, climatic conditions, tilt of the panel and soiling of the solar panels. It can be observed that the solar panels, installed as either MW-scale plants or roof-top plants, might not be cleaned due to several reasons such as scarcity of water or lack of manpower and equipment. Without a proper cleaning schedule, the panels might be cleaned either by rains or by infrequent cleaning which could be delayed by days or even weeks. 
Recently, regulations were introduced to penalize the solar power generators if their actual power generation deviated from the forecast by a margin, decided by the regulatory commission in the respective countries. For example, in India, Central Electricity Regulatory Commission (CERC) published the 'Framework on Forecasting, Scheduling and Imbalance Handling for Variable Renewable Energy Sources (Wind and Solar)' in March 2015. In case of under or overinjection of solar or wind power, deviation charges will be levied on the generators as per the guidelines mentioned in this framework. Forecasting of solar power has taken prominence in the global energy scenario and soiling factor plays a crucial role in forecasting and estimating the yield from solar power plant.

The soiling losses have been neglected by the solar power generators for a long time because soiling was not causing significant losses to the generators. But in regions where the events of dust storms are frequent or are prone to high deposition of dust on a daily basis, soiling measurement has gained significance. Irradiance and solar power predictions for sites in the Asian and African countries have special characteristics which are much different from the influences commonly known in Europe and North America. In particular, the influence of dust, aerosols and humidity on solar irradiance is more in densely populated countries than other developed countries with high solar power penetration. Across the world, with the increased need for solar power forecasting, the solar power generators must incorporate the soiling losses in their estimation for power output. The effect of aerosols, humidity or wind speed and wind direction on the soiling of panels must be investigated deeply. In order to accurately estimate the soiling losses, it is necessary to carry out a long-term experiment at the site location. The purpose of this work is to investigate the effect of dust on the performance of solar PV modules which will give an estimate of the soiling losses at the site of the solar plant. The approach and methodology developed in this work will help the solar power forecasters to incorporate a valid soiling correction factor in the PV power output while developing the solar forecasting model. The measurement of soiling losses could also be used to optimize the estimation of energy yield from solar power plant and thereby facilitate better planning of solar power plants.

\section{A. Global Soiling Studies}

Researchers in several parts of the world have studied the effect of soiling on solar PV modules. It can be noted that the Middle Eastern countries have done significant amount of research on this topic. The prevalence of perennial problem from dust storms in the deserts can be attributed as the reason for their need to carry out this study. In the year 2010, Monto Mani and Rohit Pillai have comprehensively documented the status of research in studying the impact of dust on solar PV modules along with identifying the challenges to future research on this topic [2]. Their critical appraisal was divided into two phases of study period. During Phase I (1940 - 1990), a few factors were pointed out which could have led to ambiguity in the experimental methodology. Most of the studies were conducted to investigate the effect of dust on the transmittance of glazing materials on the PV modules and the results obtained were dependent on the geographical location and tilt of the solar panels. Later during Phase II (1990 2010), the properties of dust were studied deeper by simulating dust accumulation with artificial dust particles. A table of recommendations of mitigation measures against impact of dust accumulation with respect to different climatic zones was presented in this paper.

Another comprehensive study [3] on the effect of dust on performance of solar (PV and thermal) device included a summary of all the key researches between 1942 and 2013. It showed in detail the composition and behavior of dust. The mitigation techniques listed included effective dust preventive coatings, automated mechanical cleaning systems and sensors to detect the critical point for cleaning of the surfaces.

In a study focused on analyzing the power loss due to soiling on solar panels [4], shading due to soiling was classified as hard shading and soft shading. Soft shading was due to smog in the atmosphere or dust particles whereas hard shading occurred due to accumulated dust blocks or bird droppings. It was observed that there was reduction in current due to soft shading and reduction in voltage due to hard shading. Hot spots could be caused due to hard shading which would pose a severe problem to the solar panels.

\section{Middle East}

In a review paper by Sanaz Ghazi on the effect of dust on flat surfaces, it was seen that Middle East and North Africa are home to the worst dust accumulation zones in the world [5]. A study was conducted in Egypt to understand reduction in transmittance of glass cover due to dust deposition [6]. It was observed that when dust deposition density is $4.48 \mathrm{~g} / \mathrm{m}^{2}$ the reduction in transmittance is $12.38 \%$ whereas when it is $15.84 \mathrm{~g} / \mathrm{m}^{2}$, the reduction in transmittance is as high as $52.54 \%$. Another similar study carried out in Saudi Arabia concluded that the glass covers coated with anti-reflective material showed lesser reduction in transmittance as compared to non-coated glass covers [7]. The overall transmittance reduction was $20 \%$ for dust deposition density of $5 \mathrm{~g} / \mathrm{m}^{2}$ after outdoor exposure of 45 days. Iraq was one of the Middle Eastern countries which was a victim of many occurrences of sand and dust storms. In Jordan, in an experimental study, the average degradation rate of efficiency for one day was $6.24 \%$, for one month was $11.8 \%$ and for a year was $18.74 \%$ [8]. Another study undertaken in Qatar used both field measurements and modelling for the analysis of effect of dust on PV performance [9]. It was once again proven that dust concentration alone is a weak predictor of PV soiling and performance, but it was indeed the major contributing factor. It was proposed that floating PV applications were more suitable for the hot desert climate because of reduction in dust deposition over the sea and improved energy yield as compared to mainland.

\section{Europe}

Although the dust deposition phenomenon in Central Europe is not as severe as that in the Middle East, the problem still exists. An experimental study conducted for five months in Belgium proved that there was a constant power loss between $3 \%$ and $4 \%$ [10] due to deposition of dust. A largescale experiment was conducted in countryside of Italy [11] on two $1 \mathrm{MWp}$ solar parks to determine the losses due to soiling. It is to be noted that the topography of the location of both plants was different and therefore resulted in a huge 
difference in losses reported, although all other parameters like tilt, make of the solar panels and capacity were the same. The first plant which was built on a sandy site recorded loss of $6.9 \%$ however, the one built on a more compact ground recorded a lower loss of $1.1 \%$. The Fraunhofer Institute for Solar Energy Systems assessed the performance of PV modules by monitoring the I-V curves [12]. An important observation in this study was that the partial cleaning of soiled panels had the same effect as that of partially shaded modules which could lead to creation of hotspots. The University of Malaga in Spain conducted a soiling experiment and found out that the even light rain of below 1 $\mathrm{mm}$ was sufficient to reduce the daily irradiation losses to less than $5 \%$ but long periods in summer without rain could lead to daily irradiation losses of $20 \%$.

\section{Asia}

The study on soiling of PV modules was undertaken the most in Asia. As a continent with large arid and semi-arid regions, Asia is the major source of dust in the world. Asia has contributed nearly $55 \%$ of the studies done on impact of dust on PV panels [13]. In some cases, dust deposition scenario was simulated under controlled conditions to study the effect of soiling. An experiment was conducted using different obstruction materials such as talcum, dust, sand and moss [14]. The amount of light radiation for all the cases was kept constant and it was observed that the reduction in power was the highest due to moss. A study was undertaken at Kathmandu [15] over five months and it was observed that the efficiency of dusty solar panel reduced by $29.76 \%$ corresponding to natural dust deposition of $9.6711 \mathrm{~g} / \mathrm{m}^{2}$. Apart from natural environmental conditions, a few other anthropogenic factors contribute towards soiling of solar modules. In June 2013, there was a major haze even that occurred over Singapore due to forest and agricultural land clearing fires. It was observed that across various PV systems in Singapore, the yield losses were in the range of $15-25 \%$ [16].

A study conducted by Jim et al., a low-cost artificial dust deposition technique was used to study the effect of soiling losses on PV modules in different locations in India [17]. The soil samples covered diverse climatic conditions and were from six different geographic locations in India. The dust sample from Mumbai showed the highest soiling loss followed by Pondicherry, owing to highest percentage of clay sediments. It was also shown that the effect of soiling was not same for all PV technologies. Most importantly, it was shown that the spectrum of incoming radiation was altered by the soiling layer on the surface of the PV modules. This study was carried out under controlled conditions where identical density of dust from different geographical locations was deposited on the panels to study their performance. It was suggested that future investigations on soiling should be conducted in actual conditions to incorporate the impact of dust and cleaning cycles on the energy yield from the PV plant.

During the early days of solar power penetration in the renewable energy scenario, the efficiency of the solar modules was very less. With improvement in the efficiency of the solar modules, there is more focus on optimizing the energy yield obtained from the PV panels. The fact that soiling is location specific and highly dependent on the tilt angle is well established by several researches. Many researchers have also recommended cleaning schedules and methods depending on the environmental conditions of a site [18]. The effect of aerosols, humidity or wind speed and wind direction on the soiling of panels must be investigated deeply. In order to accurately estimate the soiling losses, it is necessary to carry out a long-term experiment at the site location.

An initial study by Garg et al. in Roorkee, was on the effect of dust transmittance of glazing materials for solar collectors [19]. The experiment showed that on rainless days, there was a reduction of $8 \%$ in transmittance of glass with a tilt angle of $45^{\circ}$ after 30 days. One of the early experimentations was done in Bhopal [20] using a single $36 \mathrm{~W}$ solar panel and the parameters were measured at an interval of one hour. The accuracy of the measuring equipment is not specified, and it was reported that dust reduces the power production by $92.11 \%$ and efficiency by $89 \%$. The methodology used to conduct this experiment is not very acceptable as the degradation in the performance of PV modules reported is very high.

A detailed experimental study was conducted at Vellore Institute of Technology [21] using a set of three monocrystalline and polycrystalline modules each. It was observed that the dust deposition was highest for panels with $0^{\circ}$ tilt angle whereas the efficiencies were higher for the panels mounted with $30^{\circ}$ tilt angle. At IISC Bengaluru, the effect of dust was studied through indoor simulation and outdoor experimentation [22]. The amount of dust deposited in indoor simulation was higher and therefore the reduction in maximum power output was $45-55 \%$ whereas in the outdoor set-up, subjected to natural soiling, the reduction was only 5-6\%. In the indoor set-up, the dusty panels showed an increase in the module temperatures in the range of $1-2{ }^{\circ} \mathrm{C}$ higher than the cleaned panels. However, in the outdoor setup, no significant temperature differences were observed.

A case study in Maharashtra on roof top PV systems showed that soiling decreased power production by $2-3 \%$ [23]. It was also noticed that if soiling was not addressed, it could lead to permanent hotspots which decreased life of PV modules. An analysis of the PV yield losses due to soiling was carried out in New Delhi, which is one of the most polluted cities in India. The daily soling loss accumulation rates of $0.3 \%$ to $0.6 \%$ were reported during the study period of 3-4 months. A key finding in this analysis was that the performance ratio of the solar plants improved in the range of $27-39 \%$.

\section{B. Effect of Environmental Parameters on Soiling}

Several environmental parameters have varied influence on the rate of soiling of PV modules. In 2017, Wasim Javed and team applied artificial neural network for modelling the relationship between soiling loss and environmental variables. This study was undertaken in Qatar and indicated that PV soling loss is a complex function of environmental variables [24]. However, it was also seen that the correlation between soiling loss and any individual environmental variable was weak and therefore there were several other factors which influenced the PV performance loss due to soiling. 


\section{Wind Speed}

The deposition of dust depends on the wind speed and its direction. The lift and transportation of dust particles is dictated by wind. The role of wind in deposition and removal of dust from the surface of the PV modules is a function of wind speed and direction. Goosens et al. conducted wind tunnel experiments and field investigations to study the eolian dust deposition on solar collectors [25]. It was observed that at wind speeds $0.57 \mathrm{~m} / \mathrm{s}$, the dust deposition was lesser when compared to dust deposition for wind speed higher than 0.95 $\mathrm{m} / \mathrm{s}$. It was also noted that the deposition of dust with respect to elevation decreases with increased wind speeds. Wind also removes deposited dust, and the rate of dust removal is more effective for high tilt angle of the PV module [18]. The dust deposition and removal by wind also depends on size and mass of the dust particles [3]. A dust storm can reduce the power output of a solar module drastically. It can be as high as $15 \%$ reduction in PV module efficiency for a period of one month in the dust storms [9].

\section{Rainfall}

It is very common to see that the solar PV modules are left to be cleaned by the rains if there is no proper cleaning schedule maintained which could be due to scarcity of water or lack of adequate manpower to clean the panels. Rain is considered as a restorative method for PV modules whose efficiency was reduced due to soiling. It should also be noted that light rainfall can increase the problem of soiling because the rain droplets can collect the airborne particulate matter and deposit them on the surface of PV modules. Less rainfall can lead to dust accumulation on the lower cell rows which causes partial shading leading to formation of hotspots [12]. A study in California showed that a rainfall event had recovered most of the lost PV efficiency which went back to $7.1 \%$ from $5.6 \%$ [26]. While studying the seasonal effect of dust on performance of PV modules, it was observed that the seasons with less rainfall showed higher dust deposition compared to those seasons with higher rainfall [27].

\section{Humidity}

One of the other important factors which are responsible for dust accumulation is humidity. High humidity can result in formation of dew on the PV module surface which can lead to coagulation of dust. This leads to formation of sticky dust layers on the surface. It is observed that the dust accumulation begins to increase with a gradual decrease of relative humidity. Through research, it was established that there was a formation of water capillary bridge between dust particles and glass surface which was caused by humidity. It was proven that there is a weak negative correlation between humidity and dust accumulation [14]. High wind velocity leads to decreased relative humidity which results in high PV efficiency.

\section{MATERIALS AND METHODS}

\section{A. Methodology to Analyze Performance of $20 \mathrm{~kW}$ Solar Power Plant}

For analysis, the data of the environmental parameters was extracted from the server at National Institute of Wind Energy (NIWE) for the ten months from January to October of the year 2018. The electrical parameters of the solar power plant were downloaded from the Growatt inverter web portal. All the values logged were instantaneous values. The PV module conversion efficiency and the performance ratio values were calculated to analyze the performance of the plant.

The instantaneous PV module conversion efficiency is calculated as [27]:

$$
\eta_{P V}=\frac{P_{D C}}{G_{t} * A_{s}}
$$

where, AS - Total surface are of the Solar PV modules; $\mathrm{P}_{\mathrm{DC}}$ - DC power output of the solar PV module;

$\mathrm{G}_{\mathrm{t}}$ - Total inplane irradiation.

Ahmad Mohd Khalid et al. recommended that the PR be calculated according to the IEC 61274 standard titled "Photovoltaic system performance monitoring Guidelines for measurement, data exchange and analysis". According to their study, this methodology is highly beneficial for countries to assess the performance of the grid connected PV systems.

The PR of the solar power plant is calculated as [28]:

$$
Y_{F}=\frac{E_{A C}}{P_{o}}
$$

The final yield $\mathrm{Y}_{\mathrm{F}}$ is the ratio of the total useful output energy to the nominal power of the PV system. $\mathrm{E}_{\mathrm{AC}}$ is total useful output energy and $\mathrm{P}_{\mathrm{O}}$ is nominal power of the PV system.

The reference yield $Y_{R}$ is the ratio of the total inplane irradiation to the PV's reference irradiance.

$$
Y_{R}=\frac{G_{t}}{G_{I}} * \tau_{t}
$$

where $\mathrm{G}_{\mathrm{I}}=1 \mathrm{~kW} / \mathrm{m}^{2}$ and $\tau_{\mathrm{t}}$ is the corresponding time interval.

Performance Ratio (PR) is the ratio of the final yield to the reference yield.

$$
P R=\frac{Y_{F}}{Y_{R}}
$$

The above formulae were coded on MATLAB and the results are tabulated in a Microsoft Excel file. Since the time interval between the instantaneous values of the electrical parameters was not constant, the environmental parameters were manually averaged by visual inspection of the time stamp of the data. The effect of environmental factors on the performance of the PV plant was analyzed using linear regression on Microsoft Excel.

\section{B. Methodology to Analyze the Result of Soiling Experiment}

The current drawn from a solar panel is proportional to the incident solar radiation. Two identical solar panels (80 W each) were used in this set-up. Therefore, the experiment was designed to measure the power drawn from the panels to arrive at a soiling loss estimation.

Although, both the panels were similar in make and specifications, their performances were not identical. Therefore, the current drawn from each panel varied at all instants. To estimate the difference in performance, the 
panels were tested for five days from 2nd July to 6th July 2018. The GHI and GTI data were plotted for all the five days. It was concluded by visual observation that 5 July 2018 was a clear sky day. The slope of the line joining the current points on the scatter plot on 5th July 2018 was chosen as the reference slope. It was referred to as Slope_cleaned $=0.9831$ for the calculation of soiling loss.

Before the start of the experiment, both the PV panels were thoroughly cleaned. One solar panel was cleaned every day. The soiled panel was cleaned at various intervals to analyze soiling. Ideally, the soiled panel should be cleaned after two weeks. During monsoon, the amount of dust deposition on the panels was less. Therefore, the soiled panel was cleaned after one month. The weather conditions for each day were observed and noted. A cleaning schedule was duly maintained with observations of each day noted. To estimate the soiling loss, the output of the clean PV panel and the soiled PV panel were compared.

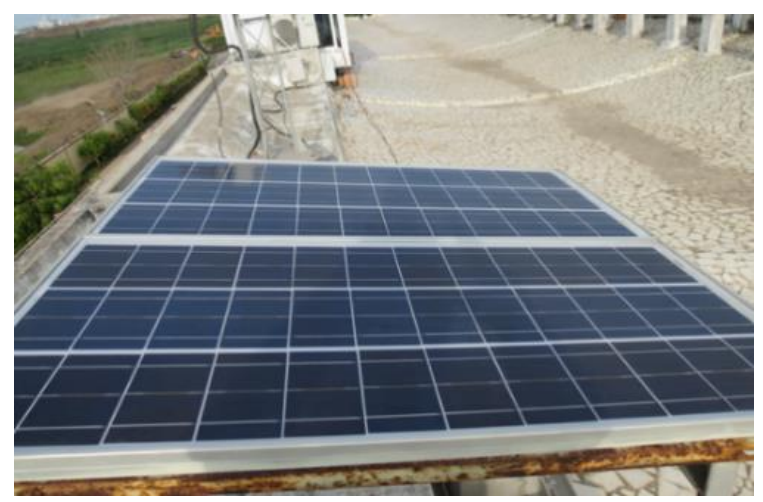

Fig. 1. $80 \mathrm{~W}$ Solar Panels.

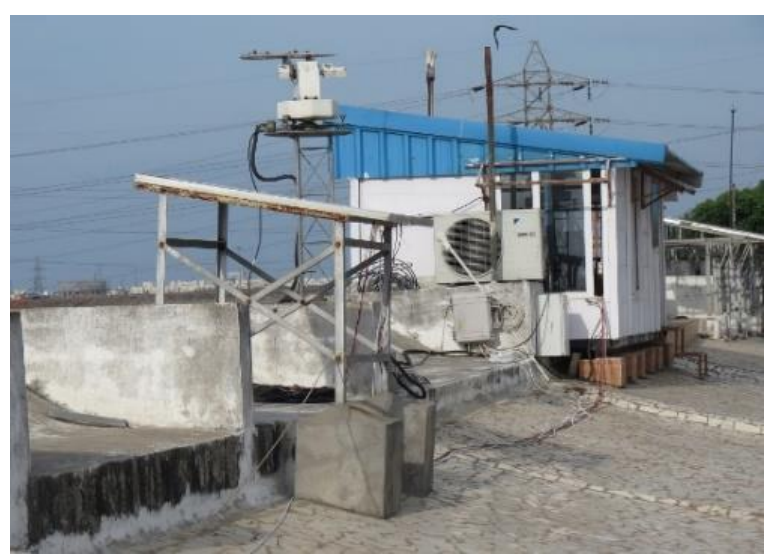

Fig. 2. Experimental set-up location.,

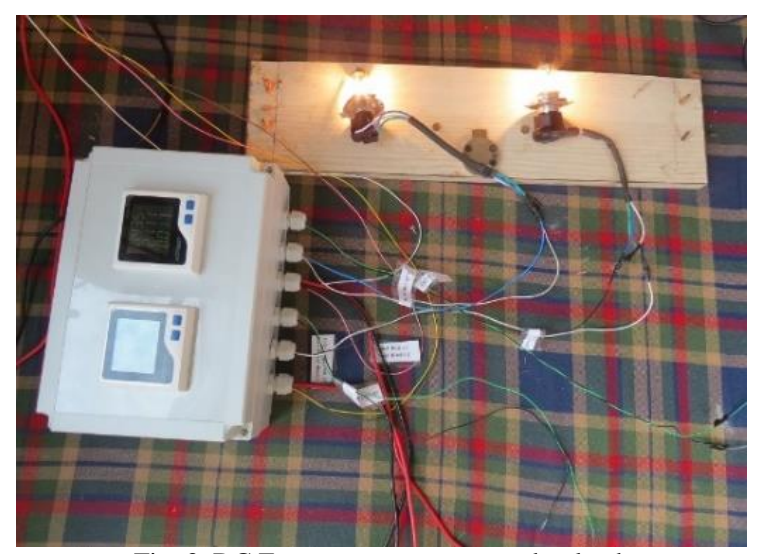

Fig. 3. DC Energy meters connected to load.

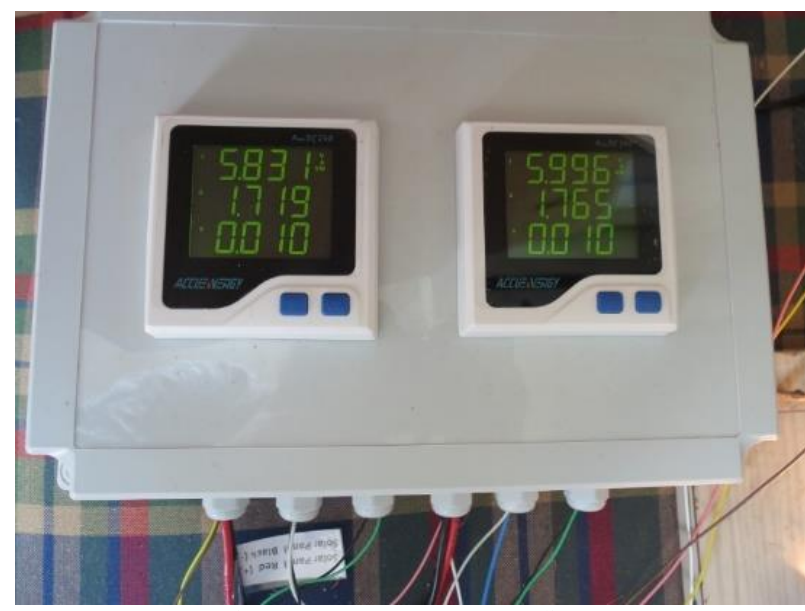

Fig. 4. DC Energy meter readings.

The current drawn from the solar panel is directly proportional to the incident solar radiation. The current of the solar panels was the parameter used to estimate the soiling loss. The current drawn from the cleaned panel ( $\left.\mathrm{I}_{\text {cleaned }}\right)$ was plotted on $\mathrm{X}$-axis and current drawn from soiled panel $\left(\mathrm{I}_{\text {soiled }}\right)$ was plotted on Y-axis. The slope of line joining the current points in the scatter plot is Slope _soiled.

The formula used for estimating the soiling factor is as follows:

$$
\text { Soiling Loss }(\%)=\left(1-\frac{\text { Slope }_{\text {soiled }}}{\text { Slope }_{\text {cleaned }}}\right) \times 100
$$

\section{RESULTS AND DISCUSSION}

\section{A. Performance Analysis of $20 \mathrm{~kW}$ Solar Power Plant}

The input data for the analysis was filtered manually by visual inspection of the timestamp of the SRRA data and Growatt inverter data. The data was processed on MATLAB and Microsoft Excel to obtain the results. It was observed that the correlation between module temperature and DC power; between humidity and DC power; between humidity and DC power varied every month. The coefficient of determination $\left(\mathrm{R}^{2}\right)$ values for each correlation are tabulated below.

TABLE I: CORRELATION BETWEEN DC POWER AND ENVIRONMENTAL

\begin{tabular}{lccc}
\multicolumn{3}{c}{ PARAMETERS } \\
\hline $\begin{array}{l}\text { Environmental } \\
\text { Parameters }\end{array}$ & January R $(\%)$ & $\begin{array}{c}\text { February R } \\
(\%)\end{array}$ & March R $^{2}(\%)$ \\
\hline $\begin{array}{l}\text { Global Tilted } \\
\text { Irradiation }\end{array}$ & 90.54 & 92.37 & 90.29 \\
Ambient & 29.11 & 28.43 & 27.85 \\
Temperature & 22.45 & 23.17 & 27.72 \\
Relative Humidity & 3.28 & 6.95 & 1.03 \\
Wind Speed & & & \\
\hline
\end{tabular}

TABLE II: CORRELATION BETWEEN DC POWER AND ENVIRONMENTAL PARAMETERS

\begin{tabular}{cccc}
\hline $\begin{array}{c}\text { Environmental } \\
\text { Parameters }\end{array}$ & April R $^{2}(\%)$ & May R $^{2}(\%)$ & June R $^{2}(\%)$ \\
\hline $\begin{array}{c}\text { Global Tilted } \\
\text { Irradiation } \\
\text { Ambient }\end{array}$ & 90.54 & 96.18 & 95.20 \\
$\begin{array}{c}\text { Temperature } \\
\text { Module }\end{array}$ & 29.11 & 68.77 & 43.09 \\
$\begin{array}{c}\text { Temperature } \\
\text { Relative }\end{array}$ & - & - & 84.47 \\
Humidity & 22.46 & 68.74 & 29.79 \\
Wind Speed & 3.29 & 1.05 & 4.50 \\
\hline
\end{tabular}


The PV conversion efficiency and the performance ratio (PR) of the 20-kW power plant from January to June 2019 are tabulated below.

TABLE III: PV CONVERSION EFFICIENCY AND PR

\begin{tabular}{ccc}
\multicolumn{2}{c}{ TABLE III: PV CONVERSION EFFICIENCY AND PR } \\
\hline \multirow{2}{*}{ Month } & $\begin{array}{c}\text { PV Conversion } \\
\text { Efficiency }(\%)\end{array}$ & PR (\%) \\
\hline January & 12.19 & 78 \\
February & 11.95 & 76 \\
March & 12.07 & 77 \\
April & 12.19 & 78 \\
May & 12.08 & 77 \\
June & 10.03 & 64 \\
\hline
\end{tabular}

A very important observation was made in the month of June with regard to module temperature. Temperature sensor

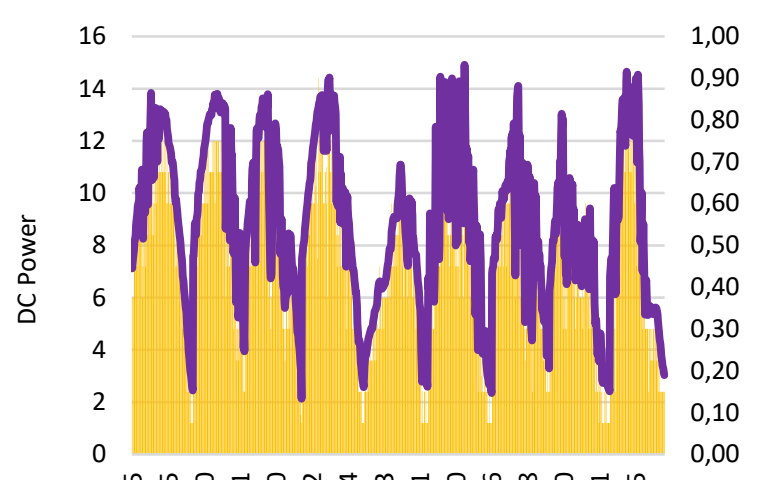

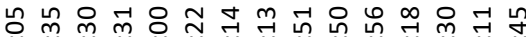
ษ்

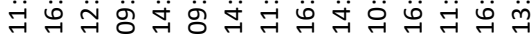
넉ㄱㄱ

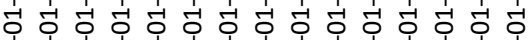

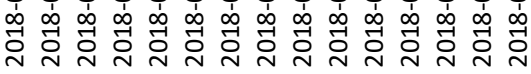

DC Power (kW) GTI (kW/m2)

Fig. 5. Correlation between GTI and DC Power.

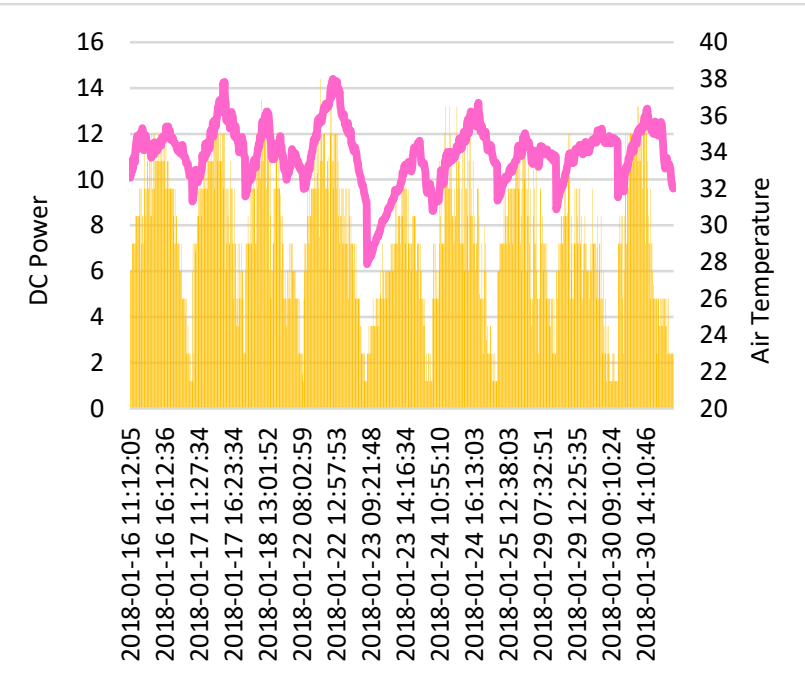

DC Power (kW) Air temperature (deg. C)

Fig. 6. Correlation between Air temperature and DC Power. was attached on the back of one of the $255 \mathrm{~W}$ panels in the $20-\mathrm{kW}$ power plant. It was observed that there was a correlation of $84.47 \%$ between the DC power and module temperature whereas it was only $43.09 \%$ between ambient temperature and DC power. This observation emphasized on the need for module temperature sensors for the measurement of actual temperature of the solar panel. The maximum module temperature reached $66.33^{\circ} \mathrm{C}$ whereas the maximum ambient temperature was only $37.84{ }^{\circ} \mathrm{C}$.

The graphs for performance analysis of the $20-\mathrm{kW}$ power plant for nine days in the month of June 2018 are shown below. The correlation between the DC power and the environmental parameters can be clearly observed in these graphs.

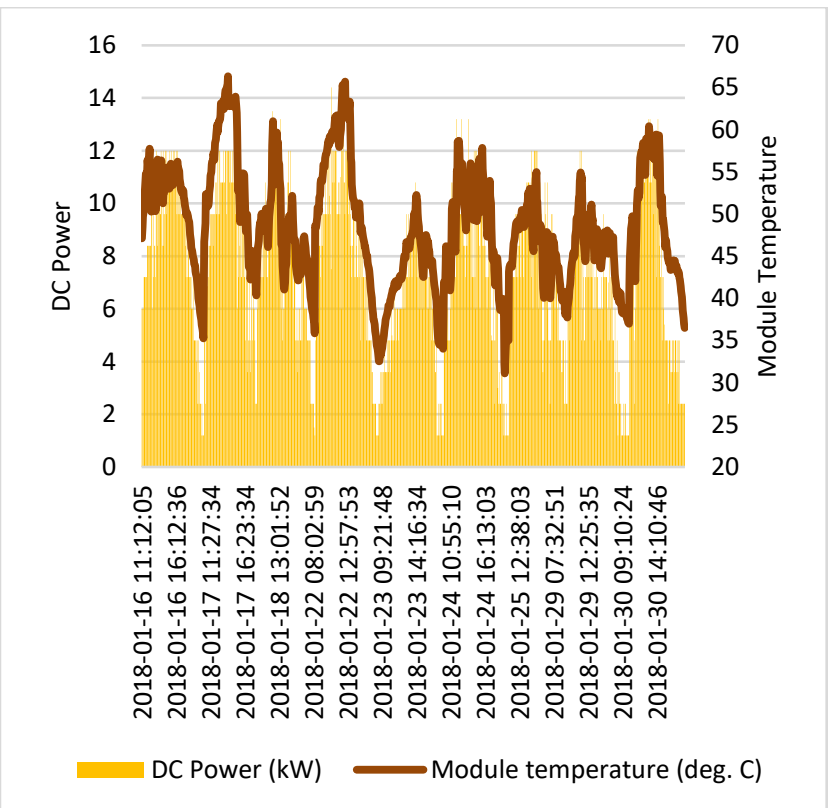

Fig. 7. Correlation between Module temperature and DC Power.

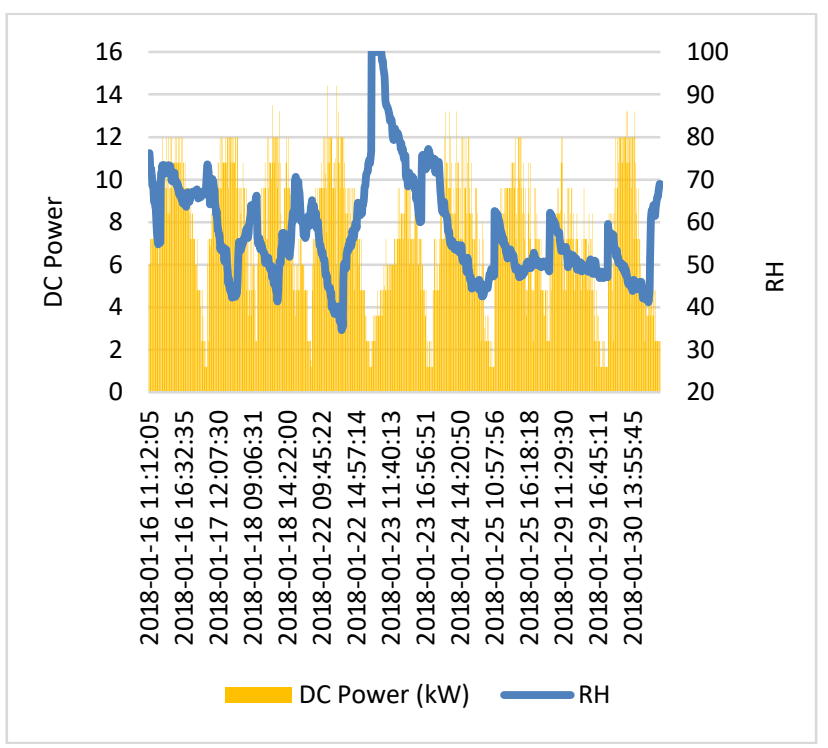

Fig. 8. Correlation between RH and DC Power. 


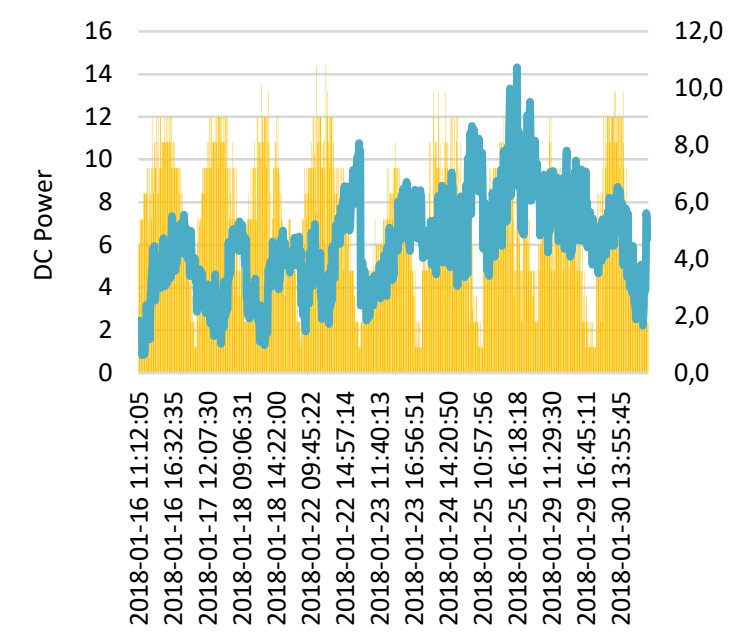

DC Power $(k W) \quad$ Wind Speed $(\mathrm{m} / \mathrm{s})$

Fig. 9. Correlation between Wind Speed and DC Power.

\section{B. Performance Analysis of $20 \mathrm{~kW}$ Solar Power Plant}

From 1st June 2018 to 25 th June 2019, there were 153 days of data which qualified for the analysis. On these days, one panel was cleaned whereas the other panel was left for natural soiling on an average for a period of one month. There were 67 rain days out of the 153 days of data collection. When the amount of rainfall was less, the soiling loss increased whereas for heavy rain, the soiling loss value was negative indicating that the panel performance improved significantly. During the said period of observation, the soiling loss varied from $1.36 \%$ to $3.67 \%$. Soiling loss was estimated for each day of observation, and it varied depending on the amount of rainfall and other environmental factors.

The minimum and maximum soiling loss for every month during the experiment are tabulated as shown below. From the table below it is observed that when the amount of rainfall was $0.3 \mathrm{~mm}$ on 28th June 2018, the soiling loss increased from $1.67 \%$ to $1.92 \%$. When the amount of rainfall was 2.4 $\mathrm{mm}$ on 6 th June 2018, the soiling loss decreased from $0.83 \%$ to $0.78 \%$. During the course of the experiment, it was observed that the soiling losses were lowest, less than $1 \%$ on all days, in February 2019. The soiling losses touched the highest value of 3.6\% in May and June 2019.

TABLE IV: MINIMUM AND MAXIMUM SOILING LOSSES FOR EVERY MONTH

\begin{tabular}{cccc}
\hline Month & Rain (mm) & $\begin{array}{c}\text { Min. SL } \\
(\%)\end{array}$ & $\begin{array}{c}\text { Max. SL } \\
(\%)\end{array}$ \\
\hline June 2018 & 8.2 & 0.41 & 1.92 \\
July 2018 & 66.4 & -0.25 & 1.31 \\
August 2018 & 46.2 & -0.78 & 1.91 \\
September 2018 & 96.9 & -0.74 & 0.76 \\
October 2018 & 17.2 & 0.52 & 1.97 \\
November 2018 & 18.0 & -0.09 & 1.87 \\
December 2018 & 15.9 & -0.92 & 0.33 \\
January 2019 & - & - & - \\
February 2019 & 0.8 & -1.35 & 2.99 \\
March 2019 & 0.1 & -0.49 & 1.59 \\
April 2019 & 0.3 & -0.62 & 2.73 \\
May 2019 & 0.6 & -0.14 & 3.61 \\
June 2019 & 1.1 & -0.62 & 3.67 \\
\hline
\end{tabular}

The soiling factor that obtained after the analysis in this experiment would be incorporated into the solar forecasting chain. There are several blocks in the forecasting chain which includes important conversion models. The soiling factor would an input to the block that converts DC power to AC power.

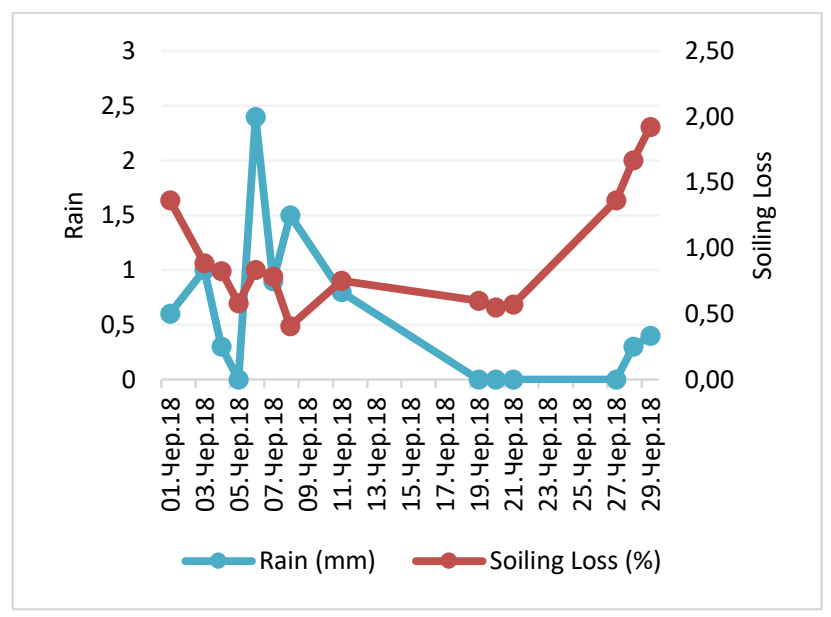

Fig. 10. Soiling analysis - June 20.

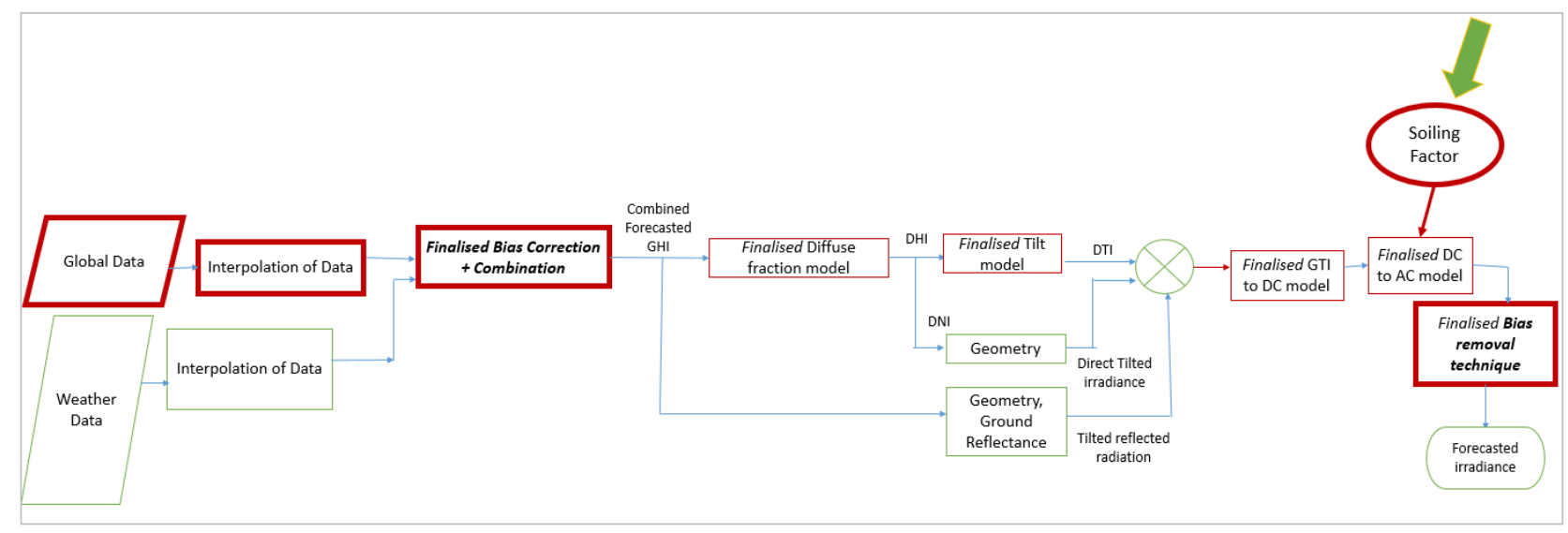

Fig. 11. Solar Forecasting Model Chain.

\section{CONCLUSION}

In this work, a detailed study was undertaken to analyze the effect of soiling on performance of PV plants and the results were documented. The performance of $20 \mathrm{~kW}$ rooftop solar power plant was analyzed. The correlation between module temperature and DC power; between humidity and DC power; between GTI and DC power varied every month. 
The highest correlation was observed between GTI and DC power whereas the least correlation was observed between wind speed and DC power. The correlation between module temperature and DC power was almost twice the correlation observed between ambient temperature and DC power. Therefore, it is important to measure the module temperature to gauge the performance of a solar panel.

The experiment for the estimation of soiling losses successfully set-up at NIWE, was continued further to estimate the soiling losses for future analysis. The study was undertaken from 1st June 2018 to 25th June 2019 and there were 153 days which qualified for the soiling analysis. During the said period of observation, the soiling loss varied from $-1.36 \%$ to $3.67 \%$. The methodology developed to study the soiling losses in this work can be extended to other reallife PV plants across the world. It is important to carry out the experiment more diligently and collect the data of soiling for the maximum number of days in a year. It is advised to compulsorily undertake soiling analysis for all solar power plants with installed capacity of $5 \mathrm{MW}$ and above.

This work is a part of the broader ongoing activities carried out at the Deutsche Gesellschaft für Internationale Zusammenarbeit GmbH (GIZ) under the Green Energy Corridors Project. As the need for optimization of yield from Solar PV plants increases, soiling correction factor play a crucial role in forecasting solar power. The longer the duration of soiling experiment, the estimation of soiling losses will be more reliable. It is important that the soiling experiment be carried out for at least one year at the site location. No generalized soiling factor can be derived for the various sites in different regions. Soiling factor must be incorporated into the day-ahead forecasting model because the amount of soiling varied daily. As a result, the soiling factor for each day in a year must be calculated. Weekly or monthly average values of the soiling factor will only lead to errors in forecasting because it will not be able to reflect the soiling losses accurately. The experimental set-up designed for this work was successful in estimating the soiling loss factor. This work could pave way for further research and analysis on effect of soiling on performance of solar PV modules and yield assessment of solar power plants in India.

\section{APPENDIX}

$\begin{array}{cl}\text { Abbreviations and Acronyms } \\ \text { PV } & \text { Photovoltaic } \\ \text { GTI } & \text { Global Tilted Irradiation } \\ \text { GHI } & \text { Global Horizontal Irradiation } \\ \text { MNRE } & \text { Ministry of New and Renewable Energy } \\ \text { CERC } & \text { Central Electricity Regulatory Commission } \\ \text { SLDC } & \text { State Load Despatch Centre } \\ \text { SRRA } & \text { Solar Radiation Resource Assessment } \\ \text { NIWE } & \text { National Institute of Wind Energy } \\ \eta_{P V} & \text { PV module conversion efficiency } \\ P_{D C} & \text { DC power output of the solar PV module } \\ A_{s} & \text { Total surface are of the Solar PV modules } \\ G_{t} & \text { Total inplane irradiation } \\ Y_{F} & \text { Final yield } \\ E_{A C} & \text { Total useful output energy } \\ P_{o} & \text { Nominal power of the PV system } \\ Y_{R} & \text { Reference yield } \\ G_{I} & \text { Reference irradiation }\left(1 \mathrm{~kW} / \mathrm{m}^{2}\right) \\ \tau_{t} & \text { Time Interval } \\ \text { PR } & \text { Performance Ratio } \\ \mathrm{I}_{c l e a n e d} & \text { Current drawn from the cleaned panel }\end{array}$

$\begin{array}{cl}\text { Isoiled }_{\text {S }} & \text { Current drawn from the soiled panel } \\ \text { Slope_soiled } & \text { Slope of line joining the current points on scatter plot } \\ \text { Slope_cleaned } & \text { Reference slope } \\ \text { SL } & \text { Soiling Loss } \\ \text { GIZ } & \text { Deutsche Gesellschaft für Internationale } \\ \text { GEC } & \text { Zusammenarbeit GmbH } \\ & \text { Green Energy Corridors }\end{array}$

\section{ACKNOWLEDGMENT}

The work described here was conducted under the Green Energy Corridors (GEC) project of Deutsche Gesellschaft für Internationale Zusammenarbeit GmbH (GIZ). The GEC project has been funded by the Federal Ministry for Economic Cooperation and Development (Bundesministerium für wirtschaftliche Zusammenarbeit und Entwicklung, BMZ) and being implemented by GIZ GmbH under Indo-German Energy Program. The authors would also like to thank Overspeed $\mathrm{GmbH}$ for sponsoring and mentoring this work. The authors express their gratitude to National Institute of Wind Energy (NIWE), Chennai and the Ministry of New and Renewable Energy (MNRE), Government of India, for their kind cooperation and for providing environmental parameter data sets measured at the Solar Radiation Resource Assessment (SRRA) station in Chennai.

\section{REFERENCES}

[1] Reinhart Appels, B. L. B. H. H. G. A. B. R. P. K. D. M. J. D. J. P., 2013. "Effect of soiling on photovoltaic modules". Solar Energy, Volume 96, pp. 283-291.

[2] Monto Mani, R. P., 2010. Impact of dust on solar photovoltaic (PV) performance: Research status, challenges and recommendations. Renewable and Sustainable Energy Reviews, 21 July, Volume 14, pp. 3124-3131.

[3] Travis Sarver, A.-Q. L. K., 2013. A comprehensive review of the impact of dust on the use of solar energy: History, investigations, results, literature, and mitigation approaches. Renewable and Sustainable Energy Reviews, pp. 698-733.

[4] Mohammad Reza Maghami, H. H. C. G. M. A. R. M. I. R. S. H., 2016. Power loss due to soiling on solar panel: A review. Renewable and Sustainable Energy Reviews, Volume 59, pp. 1307-1316.

[5] Sanaz Ghazi, A. S. K. I., 2014. Dust effect on flat surfaces - A review paper. Renewable and Sustainable Energy Reviews, Volume 33, pp. 742-751.

[6] Hamdy K. Elminir, A. E. G. R. H. F. E.-H. M. B. K. M. A.-M., 2006. Effect of dust on the transparent cover of solar collectors. Energy Conversion and Management, Volume 47, p. 3192-3203.

[7] Syed A.M. Said, H. M. W., 2014. Fundamental studies on dust fouling effects on PV module performance. Solar Energy, Volume 107, pp. 328-337.

[8] Motasem Saidan, A. G. A. E. A. J. K. K., 2016. Experimental study on the effect of dust deposition on solar photovoltaic panels in desert environment. Renewable Energy, Volume 92, pp. 499-505.

[9] Christos Fountoukisa, B. F. L. A. M. A. A., 2018. Effects of atmospheric dust deposition on solar PV energy production in a desert environment. Solar Energy, 164(February), pp. 94-100.

[10] A. Massi Pavan, A. M. D. D. P., 2011. The effect of soiling on energy production for large-scale photovoltaic plants. Solar Energy, Volume 85, pp. 1128-1136.

[11] Christian Schill, S. B. M. K., 2014. Impact of soiling on IV-curves and efficiency of PV-modules. Solar Energy, Volume 112, pp. 259-262.

[12] Menoufi, K., 2017. Dust accumulation on the surface of photovoltaic panels: Introducing the Photovoltaic Soiling Index (PVSI). Sustainability (Switzerland), 9(6).

[13] Shaharin Anwar Sulaimana, A. K. S. M. M. M. M. M. A. B.-R., 2014. Influence of Dirt Accumulation on Performance of PV Panels. Energy Procedia, Volume 50, pp. 50-56.

[14] Basant Raj Paudyal, S. R. S., 2016. Dust accumulation effects on efficiency of solar PV modules for off grid purpose: A case study of Kathmandu. Solar Energy, Volume 135, pp. 103-110. 
[15] Andre M. Nobre, S. K. H. L. D. Y. F. R. M. E. B. P. R. R. T. R. I. M. P., 2016. On the impact of haze on the yield of photovoltaic systems in Singapore. Renewable Energy, Volume 89, pp. 389-400.

[16] Jim J. John, S. W. G. T. a. A. K., 2016. Study of Soiling Loss on Photovoltaic Modules with Artificially Deposited Dust of Different Gravimetric Densities and Compositions Collected from Different Locations in India. IEEE Journal of Photovoltaics, 6(1), pp. 236-243.

[17] Arash Sayyah, M. N. H. M. K. M., 2014. Energy yield loss caused by dust deposition on photovoltaic panels. Solar Energy, Volume 107, pp. 576-604.

[18] Gupta, N. M. N. a. J. P., 1990. Effect of dust on transmittance of glazing materials for solar collectors under arid zone conditions of India. Solar and Wind Technology, 7(2-3), pp. 237-243.

[19] Dayal Singh Rajput, K. S., 2013. Effect of Dust on The Performance of Solar PV Panel. International Journal of ChemTech Research, 5(3), pp. 1083-1086.

[20] Gandhi Amarnadh T, A. G. V. S. B., 2014. Investigation of the Effects of Dust Accumulation, and Performance for Mono and Poly Crystalline Silica Modules. International Journal of Renewable Energy Research, $4(3)$.

[21] Abhishek Rao, R. P. M. M. P. R., 2014. Influence of dust deposition on photovoltaic panel performance. Energy Procedia, Volume 54, pp. 690-700.

[22] Abhishek Sharma, P. J., 2016. Case study of soiling of photovoltaic panels on roof top structures. International Journal of Industrial Electronics and Electrical Engineering, 4(10), pp. 81-83.

[23] Wasim Javed, B. G. B. F., 2017. Modeling of photovoltaic soiling loss as a function of environmental variables. Solar Energy, 157(July), pp. 397-407.

[24] D Goossens, Z. Y. O. A. Z., 1993. Wind tunnel experiments and field investigations of eolian dust deposition on photovoltaic solar collectors. Solar Energy, 50(1), pp. 75-84.

[25] F. Mejia, J. K. J. L. B., 2013. The effect of dust on solar photovoltaic systems. Energy Procedia, Volume 49, pp. 2370-2376.

[26] Julius Tanesab, D. P. J. W. T. U., 2017. Seasonal effect of dust on the degradation of $\mathrm{PV}$ modules performance deployed in different climate areas. Renewable Energy, Volume 111, pp. 105-115.

[27] L.M. Ayompe, A. D. S. M. M. C., 2011. Measured performance of a $1.72 \mathrm{~kW}$ rooftop grid connected photovoltaic system in Ireland. Energy Conversion and Management, Volume 52, pp. 816-825.

[28] Ahmad Mohd Khalid, I. M. W. W. V. S., 2016. Performance ratio Crucial parameter for grid connected PV plants. Renewable and Sustainable Energy Reviews, Volume 65, pp. 1139-1158.

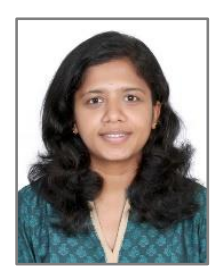

Sahana L. is presently working for GIZ GmbH for the project Indo - German Energy Program - NDC Transport Initiative for Asia (NDC-TIA). She is working on electric mobility and prior to joining GIZ, she worked with Ernst \& Young LLP on electric mobility projects for close to 2 years. She has a Master's degree in Renewable Energy Engineering and Management from TERI School of Advanced Studies, Delhi. She undertook the PV soiling project at the National Institute of Wind Energy (NIWE) in 2018 under the Indo - German Energy Program IGEN - Green Energy Corridors GEC project.

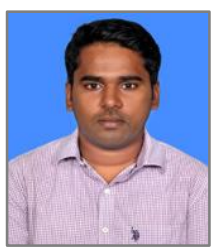

Naveen Kumar is presently working as a Solar Power Analyst at Overspeed GmbH \& Co. KG. He received his B.Eng. (2014) in Electrical and Electronics engineering, from Panimalar Engineering College, Chennai and a PG Diploma (2015) in Transmission and Distribution Systems from National Power Training Institute, Bengaluru. He joined National Institute of Wind Energy in 2018 and was involved in the development of indigenous solar forecasting infrastructure in India under the Indo - German Energy Program IGEN Green Energy Corridors (GEC) in cooperation with the Ministry on New and Renewable Energy (MNRE).

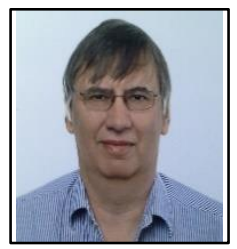

Dr. Hans-Peter Waldl, managing director Overspeed $\mathrm{GmbH}$ \& Co. KG, $\mathrm{PhD}$, is an international expert in renewable energy, wind and solar power forecasting and further education with a proven track record of more than 30 years. In India, he was lead expert of the project for developing an indigenous Indian solar power forecasting system. He has experience in teaching of Renewable Energies and their applications since 1994 in the international Postgraduate Programme Renewable Energies PPRE at Oldenburg University (in English language) and further education programs including curriculum development.

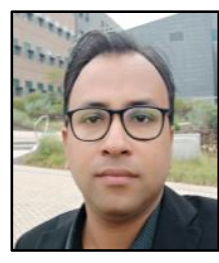

Prasun Kumar Das, is presently working as Technical Expert in GIZ GmbH. He was the Assistant Director, Technical, National Institute of Wind Energy, an R\&D institute under Ministry of new and renewable energy. He is an alumnus of Tezpur University, Assam. He has completed his M.Sc in Physics and M.Tech degree in Energy Technology. He has been actively associated solar energy research for the last ten years. Presently he is associated with Solar Radiation Resource Assessment (SRRA) Project, Calibration of Solar Sensors and RE Projects. He has published many research papers in national and international journals and guided many B.Tech/M.Tech students.

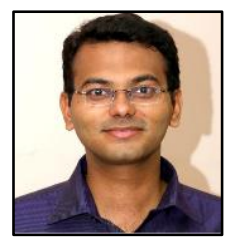

Karthik R. obtained his Bachelor's Degree in Mechanical Engineering from Anna University, Tamil Nadu. He worked as Assistant Director (Technical) in the Solar Radiation Resource Assessment unit of National Institute of Wind Energy (NIWE), Chennai. He was associated with Solar Radiation Resource Assessment (SRRA) Project and Calibration of Solar Sensors. Presently he is working as Manager - O\&M in Larsen \& Toubro (L\&T) - Solar, Chennai.

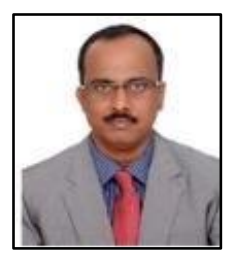

Dr K. Balaraman is the Director General- Head of National Institute of Wind Energy, Chennai. He obtained his Ph.D from Visvesvaraya Technological University. He has experience in the power sector for over 24 years and has worked in the Electricity utility in India for 14 years. Before joining NIWE he has worked as Chief General Manager in Power Research Development Consultants (Pvt.) Ltd. he is a member of many task forces constituted by Utilities and MNRE for renewable integration. He has published over 50 research papers in National, International conferences \& journals and has delivered over 1000 lectures across the Country.

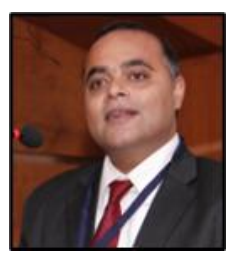

Dr. Indradip Mitra is presently working as the Head of NDC Transport Initiative for Asia (NDC-TIA) India Component project. He worked as a Senior Technical Advisor in the Indo- German Energy Programme of the German International Cooperation (GIZ GmbH) in India. He was closely associated with the Green Energy Corridors (GEC) project focusing on large scale integration of renewable energy into the Indian electricity grid. He is also active in the fields of e-mobility and long-range energy transition aspects. He was the Team Leader of the Indo - German collaborative Project 'SolMap', funded by German Federal Ministry of Environment (BMUB). He has published various papers in International and National Journals and Seminars of repute. 